\title{
A study of micro structural, magnetic and electrical properties of La-Co-Sm nanoferrites (LCSF) synthesized by sol-gel method
}

\author{
Kadhum Jassem Wadi ${ }^{1}$, Hayder Abdulameer Abbas ${ }^{2}$, Adnan Hussein Ali ${ }^{3}$, Ban Mohammad Hasan \\ 1,2,4 Middle Technical University, Technical Instructors Training Institute, Baghdad, Iraq \\ ${ }^{3}$ Middle Technical University, Institute of Technology, Baghdad, Iraq
}

\begin{tabular}{l} 
Article Info \\
\hline Article history: \\
Received Apr 8, 2019 \\
Revised Aug 24, 2019 \\
Accepted Sep 27, 2019 \\
\hline
\end{tabular}

Keywords:

Dc resistivity

FTIR

La-Co-Sm nanoferrites (LCSF)

SEM-EDX

Sol-gel method

XRD

\begin{abstract}
A Lanthanum $\left(\mathrm{La}^{3+}\right)$ doped Samarium-Cobalt nanoferrites (La_x,Co_0.2,Sm_0.2,Fe_(2-x) O_4, where $\mathrm{x}=0.0,0.5,1.0)$ have been synthesized by sol-gel method in citrate media. Obtained spinal ferrites micro structure properties have been investigated by XRD, FTIR, SEM-EDX, and TEM-SAED techniques. All the samples are nano in size with significant hysteresis. Micro structural analysis by XRD confirms the obtained samples showing the single phase cubic spinal structures with an average crystal size found from $12 \mathrm{~nm}$ to $25 \mathrm{~nm}$, while the average particles sizes identified from TEM analysis are ranging from $21.5 \mathrm{~nm}-26.8 \mathrm{~nm}(\sim 23.4 \mathrm{~nm})$ and from $20.5 \mathrm{~nm}$ to $28(\sim 26.4 \mathrm{~nm}) \mathrm{nm}$ for $\mathrm{x}=0.5,1.0$. The lattice parameter found to be $\mathrm{a}=8.402,8.423,8.467 \AA$ for the respective values of $\mathrm{x}=0.0,0.05$, and 1.0. Electrical properties show increase in dc resistivity with increase in $\mathrm{La}^{3+}$ ion concentration. Finally, it was concluded that the doping of Lanthanum ion $\left(\mathrm{La}^{3+}\right)$ in the ferrites structure is found to influencing the structural and electrical properties without scarifying the ferromagnetic character.
\end{abstract}

Copyright $(0) 2020$ Institute of Advanced Engineering and Science. All rights reserved.

\section{Corresponding Author:}

Hayder Abdulameer Abbas, Middle Technical University, Technical Instructors Training Institute, Baghdad, Iraq Email: haeder_abid71@yahoo.com

\section{INTRODUCTION}

Study of Nanoferrites is the special branch of ferromagnetics. Nanoferrites are important materials both from theoretical and industrial view. From the literature survey, if was indentified that nanoferrites are produced by variety of routs and methods viz., ball milling [1, 2], sol-gel [3-5], chemical co-precipitation [6, 7], forced hydrolysis [8] , microwave [9] , auto combustion [10], methods etc., out of all, sol gel method proved as simple and conventional one in the laboratory scale [11]. Plenty of research work done in the field of rare earth elements $\left(\mathrm{La} 3+, \mathrm{Sm}^{3+}, \mathrm{Gd}^{3+}, \mathrm{Nd}^{3+}, \mathrm{Dy}^{3+}, \mathrm{Tb}^{3+}, \mathrm{Ce}^{3+}, \mathrm{Th}^{3+}, \mathrm{Y}^{3+}, \mathrm{Eu}^{3+}\right.$ etc.,) doping on the characteristics and application of nanoferrites. Rare earth atom doped nanoferrites have huge significance in different industrial applications and treated as promising material for various modern applications; in this way, rare earth atoms assume an undeniably vital job as dopants [12]. The doping of rare earth element in place of $\mathrm{Fe} 3+$ ion in nanoferrite structure is widely practiced technique to get changes in different properties of the nanoferrites. Doping with specific rare earth atoms sometimes results in to high dc resistivity, tremendous change in electrical permittivity and very low dielectric loss [13]. A Strong relationship between the conduction process \& the dielectric conduct of the doped ferrites has been accounted for $[14,15]$.

The effects of substituted rare earth ions like $\mathrm{La}^{3+}, \mathrm{Sm}^{3+}, \mathrm{Gd}^{3+}, \mathrm{Nd}^{3+}, \mathrm{Dy}^{3+}, \mathrm{Tb}^{3+}, \mathrm{Ce}^{3+}, \mathrm{Th}^{3+}, \mathrm{Y}^{3+}$, $\mathrm{Eu}^{3+}$ etc. in $\mathrm{Fe}^{3+} \mathrm{B}$ site of ferrites have been investigated by various researchers [16] by double doping also. Rezlescu et al. [17] investigated the influence of rare earth ions $\left(\mathrm{Y}^{3+}\right)$ like $\mathrm{Sm}^{3+}, \mathrm{Er}^{3+}, \mathrm{Tb}^{3+}, \mathrm{Yb}^{3+}, \mathrm{Dy}^{3+}, \mathrm{Gd}^{3+}$, substitution on structure, magnetic and electrical properties of $\mathrm{Li}-\mathrm{Zn}$ spinal ferrites. Sattar et al. [18] 
investigated $\mathrm{Cu}-\mathrm{Zn}$ ferrites doped with $\mathrm{La}^{3+}, \mathrm{Sm}^{3+}$ and identified those higher values in density \& decrease in porosity of nanoferrites. However, from literature survey $[19,20]$, it is observed that there is no work carried out the substitution of $\mathrm{La}^{+3}$ doped 'Co-Sm' nanoferrites developed by citrate mediated sol-gel method [21]. In the present research, we decided to study the impact of $\mathrm{La}^{+3}$ on the structural and magnetic properties of La-Co-Sm nanoferrites (LCSF) with a chemical formula (La_x,Co_0.2,Sm_0.2,Fe_(2-x) [,O)_4, where $\mathrm{x}=0.0,0.5,1.0)$. The nanoparticles La-Co-Sm nanoferrites are synthesized using the sol-gel method. A discussion on the structural and magnetic properties of the samples that have been synthesized is given subsequently. In addition, we also investigated the spinal ferrites micro structure properties by XRD, FTIR, SEM-EDX, and TEM-SAED techniques. The results of our study show that the proposed methods present an increasing of Electrical properties represented by dc resistivity with increase in $\mathrm{La}^{3+}$ ion concentration.

\section{MATERIALS AND METHOD}

\subsection{Chemicals}

All chemicals/reagents used in the entire study are AR grade purchased from Merck, Sd Fine chemical. Double distilled water $(\mathrm{pH}=7.01)$ used thorough the study Tables and Figures are presented center, as shown below and cited in the manuscript.

\subsection{Synthesis of nanoferrites}

Lanthanum $\left(\mathrm{La}^{3+}\right)$ doped nanocrystalline ' $\mathrm{Co}-\mathrm{Sm}$ ' nanoferrites belonging to the series $\left(\mathrm{La}_{\mathrm{x}}, \mathrm{Co}_{0.2}, \mathrm{Sm}_{0.2}, \mathrm{Fe}_{2-\mathrm{x}}, \mathrm{O}_{4}\right.$, where $\left.\mathrm{x}=0.0,0.5,1.0\right)$ were prepared by sol-gel method. AR grade $\mathrm{La}\left(\mathrm{NO}_{3}\right)_{2} \cdot 6 \mathrm{H}_{2} \mathrm{O}, \mathrm{Sm}\left(\mathrm{NO}_{3}\right)_{3} 9 \mathrm{H}_{2} \mathrm{O}, \mathrm{Co}\left(\mathrm{NO}_{3}\right)_{2} 6 \mathrm{H}_{2} \mathrm{O} \& \mathrm{Fe}\left(\mathrm{NO}_{3}\right)_{3} \cdot 9 \mathrm{H}_{2} \mathrm{O}$, (99\% purity) were incorporated in minimum amount of double distilled water in stoichiometric quantities in volumetric flask and later transferred into beaker. Citric acid $(\mathrm{CA})\left(\mathrm{C}_{6} \mathrm{H}_{8} \mathrm{O}_{7}\right)$ was utilized as chelating specialist; metal nitrate to CA proportion was taken as 1:2 to get homogeneous, clear and no turbidity, which was blended by a magnetic stirrer at $90^{\circ} \mathrm{C}$. Besides providing large amount of heat energy for reaction to complete when it decomposes, the $\mathrm{CA}$ also acts as ligand which holds large metal ions and stabilize them. $\mathrm{NH}_{3}$ solution was added drop wise to maintain $\mathrm{pH}$ value at 7.0 finally converted in to gel and obtained gel was then dried at $120^{\circ} \mathrm{C}$. The dried gel changed over in to a dim shading cushioned powder. The powder was then ground in agate engine and strengthened at $600^{\circ} \mathrm{C}$ for 5 hours in heater and chilled off to room temperature by stopping the muffle furnace. Ferrite powder obtain in this step, after total burning is ground well and powder is transformed to pellet by using hydraulic compress. The powder and pellet are heat treated at $400^{\circ} \mathrm{C}$ for 3 hours and used for different characterizations and the total process schematically given in Figure 1.

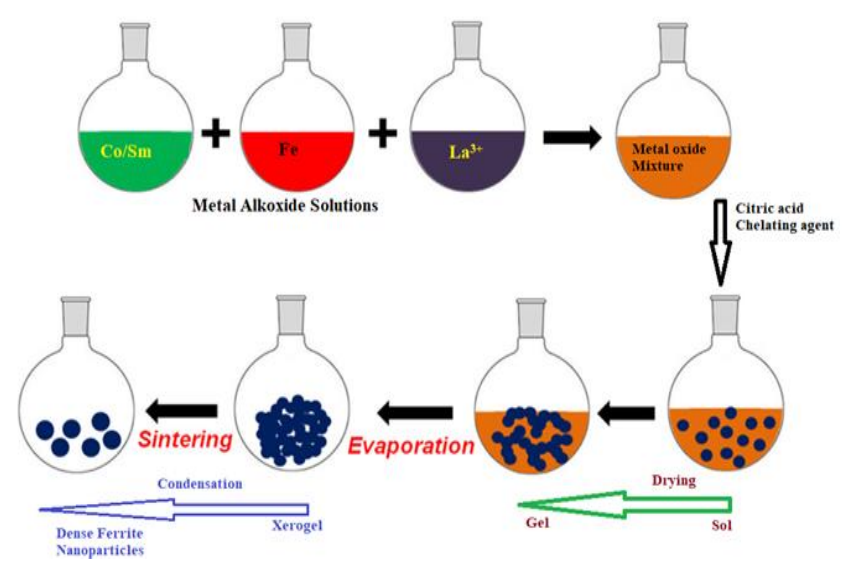

Figure 1. Schematic representation of synthesis of LCSF

\subsection{Characterization techniques}

The XRD study of three nanoferrite samples was carried out using PAN analytical X'pert Pro MRD diffraction meter with Silicon detector, and monochormatised $\mathrm{Cu} \mathrm{K} \square(\lambda=1.5410 \AA)$ as the radiation source at $40 \mathrm{KV} \& 30 \mathrm{~mA}$ with scan rate of $0.01 \mathrm{oS}$ in a 2 theta range of 10 to $80 \mathrm{oA}$, crystallite size of the nanoparticles calculated by Debye -Scherer's formula. The chemical composition of nanoferrites was examined by Fourier Transform Infrared spectroscopy in the range of 4000 to $400 \mathrm{~cm}-1$ using SHIMADZU, Perkin-Elmer model by $\mathrm{KBr}$ pellet method. LCSF surface morphology was studied by scanning electron microscope 
[(SEM JEOL, JSM 5600 model)] equipped with EDX analyzer used to determine the quantitative elemental composition. Particle size measured by Transmission Electron Microscope (TEM) using Philips, Tecnai 12, $\mathrm{G} 2$ model at $120 \mathrm{kV}$ instrument. The magnetic properties of the prepared ferrite samples obtained at room temperature $(30 \pm 1 \mathrm{oC})$. Hysteresis Tracer was employed to study the magnetic properties of the samples in the field of $10 \mathrm{kOe}$ at room temperature.

\section{RESULTS AND DISCUSSION}

\subsection{Phase formation (XRD analysis)}

XRD peaks of 『 La】_x,Co_0.2,Sm_0.2,Fe_(2-x) O_4, (where $\mathrm{x}=0.0,0.5,1.0)$ LCSF spinel nano ferrites are shown in Figure 2 The spinel structure of prepared LCSF confirmed by the indexed peaks appeared at $2 \theta$ values 30.1 (220), 36.4 (311), 37.4 (222), 43.7 (400), 53.1 (422), 57.8 (511), 62.5 (440) and 76.9 (532) with small amounts of $\mathrm{La} 2 \mathrm{O} 3$ phase. XRD analysis suggested that, the doping element $\left(\mathrm{La}^{3+}\right)$ have been successfully substituted in the spinel ferrite structures and it was further supported by prepared nanoferrites samples appears in single phase face centered cubic (fcc) structure. It was further implying that the $\mathrm{La}^{3+}$ ions have been completely dissolved in to the spinal lattice of Sm-Co Ferrite [22]. Very few considerable changes were found in the relative intensities of the patterns related to the occupation of crystallographic sites of the lattice structure and nanometer size of the crystallite.

LCSF particle sizes identified in the range of $12 \mathrm{~nm}$ to $25 \mathrm{~nm}$ Table 1 calculated from the broadening of XRD intense peaks. Particles sizes obtained in the XRD analysis further supported by TEM analysis. Toksha B.G. et al. [23, 24] has been studied Cobalt ferrites with particle sizes 11-40nm by in Sol-Gel method resemble with the LCSF (current study) and saturation magnetization for pure Cobalt spinel nanoferrites is very close to the obtained results Table 1, it was also identified that remanence and coercivity are little higher than the obtained results. The lattice parameter $(a)$ of the unit cell calculated by the following Bragg's Equation [25]:

$$
a=d_{h k l} \sqrt{h^{2}}+k^{2}+l^{2}
$$

Where, 'd' is interred planar distance and $h k l$ is miller indices $\mathrm{X}$-ray density $\left(\rho_{\mathrm{x}}\right)$ has been calculated form the following equation

$$
\begin{aligned}
& \rho_{\mathrm{x}}=\frac{2 M}{N_{a} V_{\text {Cell }}} \\
& V_{\text {Cell }}=\frac{\sqrt{3}}{2} a^{2} \mathrm{c}
\end{aligned}
$$

Where, the number 2 indicates the formula units in a unit cell, Molar mass $\mathrm{M}$, and ' $\mathrm{Na}$ ' is the Avogadro number. Obtained results are tabulated in Table 1. The change in the lattice values may be expected by the replacement of $\mathrm{Fe}^{3+}, \mathrm{Co}^{3+}$, and $\mathrm{Sm}^{3+}$ ion with doping ion Lanthanum $\left(\mathrm{La}^{3+}\right)$ [26]. It was identified from the Table 1, 'd' value, lattice parameters, particle size and x-ray density values decrease with increase of the doping element $\left(\mathrm{La}^{3+}\right)$, which is explained on the basis of ionic radii values. The replacement of lower ionic radius $\mathrm{Sm}(0.096 \mathrm{~nm})$, Co $(0.075 \mathrm{~nm})$ and Fe $(0.078 \mathrm{~nm})$ by higher covalent radius element La $(0.103 \mathrm{~nm})$ may result the change in ' $\mathrm{a}$ ' and density values. This result shows that the crystal structure of LCSF spinel ferrites contracted due to the substitution of La3+ elements [27, 28]. Doping of extensive amount of rare earth element $\left(\mathrm{La}^{3+}\right)$ ion concentration leads to distorted td and oh symmetry of LCSF watching out to generation $\mathrm{Fe}^{3+}$ gaps, which further decreases in lattice parameter. At higher concentration $(\mathrm{x}=1.0)$ of $\mathrm{La}^{3+}$ ions in Sm-Co ferrite lattice the crystal size decreases. Lattice parameters obtained in the present study are in the good agreement with literature [29].

\begin{tabular}{|c|c|c|c|c|c|c|c|c|c|}
\hline $\mathrm{NO}$ & $\begin{array}{c}\text { Spinal } \\
\text { Nanoferrite } \\
\text { composition }\end{array}$ & $\begin{array}{l}\text { Particle } \\
\text { Sizes } \\
(\mathrm{nm})\end{array}$ & $\begin{array}{c}\text { Spinal } \\
\text { Lattice } \\
\text { par. (a) } \AA\end{array}$ & $\begin{array}{c}\text { x-ay } \\
\text { Density } \\
\square_{\mathrm{x}}(\mathrm{g} / \mathrm{cm})\end{array}$ & $\begin{array}{l}\text { Crystallit } \\
\text { e size } \\
(\mathrm{nm})\end{array}$ & $\begin{array}{c}\text { Saturation } \\
\text { magnetization } \\
\left(\mathrm{M}_{\mathrm{s}}\right)\end{array}$ & $\begin{array}{c}\text { Remanent } \\
\text { magnetization } \\
\left(\mathrm{M}_{\mathrm{R}}\right)(\mathrm{emu} / \mathrm{g})\end{array}$ & $\begin{array}{l}\text { Coercivity } \\
\qquad\left(\mathrm{H}_{\mathrm{c}}\right) \mathrm{O}_{\mathrm{e}}\end{array}$ & $\mathrm{R}$ \\
\hline & $\begin{array}{c}\mathrm{La}_{0} \mathrm{Co}_{0.2}, \mathrm{Sm}_{0.2} \\
\mathrm{Fe}_{2} \mathrm{O}_{4}\end{array}$ & 25.04 & 8.402 & 5.421 & $\begin{array}{c}12.05 \pm 0 . \\
02\end{array}$ & 62.54 & 19.27 & 1522.02 & 0.308 \\
\hline & $\begin{array}{c}\mathrm{La}_{0.5}, \mathrm{Co}_{0.2}, \mathrm{Sm}_{0} \\
{ }_{2}, \mathrm{Fe}_{1.5} \mathrm{O}_{4}\end{array}$ & 20.18 & 8.423 & 5.523 & $\begin{array}{c}16.25 \pm 0 . \\
04\end{array}$ & 48.70 & 16.81 & 1302.61 & 0.345 \\
\hline & $\begin{array}{c}\mathrm{La}_{1.0}, \mathrm{Co}_{0.2}, \mathrm{Sm}_{0 .} \\
{ }_{2}, \mathrm{Fe}_{1,}, \mathrm{O}_{4}\end{array}$ & 12.04 & 8.467 & 5.627 & $\begin{array}{c}25.30 \pm 0 . \\
03\end{array}$ & 27.67 & 14.37 & 1057.57 & 0.498 \\
\hline
\end{tabular}

Table 1. Effect of $\mathrm{La}^{3+}$ doping on the lattice parameter (a), crystallite size (nm) and mag. parameters of Co-Sm nanoferrites 


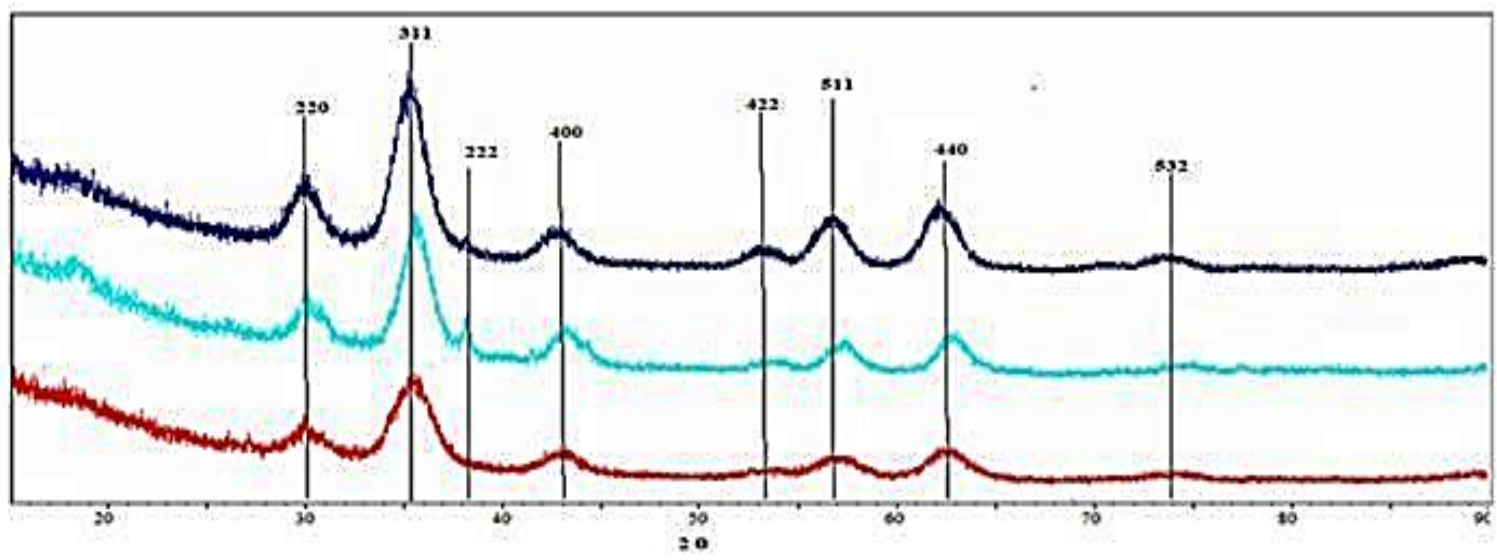

Figure 2. XRD pattern of $\mathrm{La}_{\mathrm{x}}, \mathrm{Co}_{0.2}, \mathrm{Sm}_{0.2}, \mathrm{Fe}_{2-\mathrm{x}} \mathrm{O}_{4}$, (where $\left.\mathrm{x}=0.0,0.5,1.0\right)$ (LCSF) nanoferrites

\subsection{Phase purity (FTIR analysis)}

The Fourier Transform Infrared Spectroscopy (FTIR) is an emerging tool to identify the purity of the spinel ferrites and nature of chemical bonding. In addition to the XRD study. The FTIR spectra of LCSF samples is shown in Figure 3 [30,31]. Intense peaks in the range of $3400 \mathrm{~cm}-1$ to $1600 \mathrm{~cm}-1$ can be associated with $-\mathrm{O}-\mathrm{H}$ stretching and bending vibration peaks of free of adsorbed water or in the form of moisture content. Low intense broad peak at $\sim 3415 \mathrm{~cm}-1$ in three samples assigned to $-\mathrm{O}-\mathrm{H}$ stretching vibration peaks. A medium intense peak in the Figure 3 at $1099 \mathrm{~cm}-1$ represents the $-\mathrm{O}-\mathrm{H}$ bending vibration [32]. The absorption bands $v 1$ around the value $604 \mathrm{~cm}-1$ and $v 2$ around the values $465 \mathrm{~cm}-1$ are assigned to the intrinsic stretching vibrations of ' $\mathrm{td}$ ' complexes and ' $\mathrm{Oh}$ ' complexes respectively. The presence of the above absorption bands corresponds to the $(\mathrm{M} \rightarrow \mathrm{O})$ metal-oxygen bonds in spinel ferrites $[33,34]$. The absorption bands $v 1$ and $v 2$ are slightly shifts to higher frequency, due to addition of Lanthanum ions $\left(\mathrm{La}^{3+}\right)$ content. The distinction in the frequencies of $v 1$ and $v 2$ is because of the adjustments in bond length $\left(\mathrm{Fe}^{+3} \rightarrow \mathrm{O}^{-2}\right)$ at tetrahedral (td) and octahedral (oh) sites. The groups at $604 \mathrm{~cm}-1$ and $465 \mathrm{~cm}-1$ spoke to td and oh complexes of LCSF spinal nanoferrites, individually. The IR vibration frequencies are observed to be in great concurrence with the standard literature [35, 36].

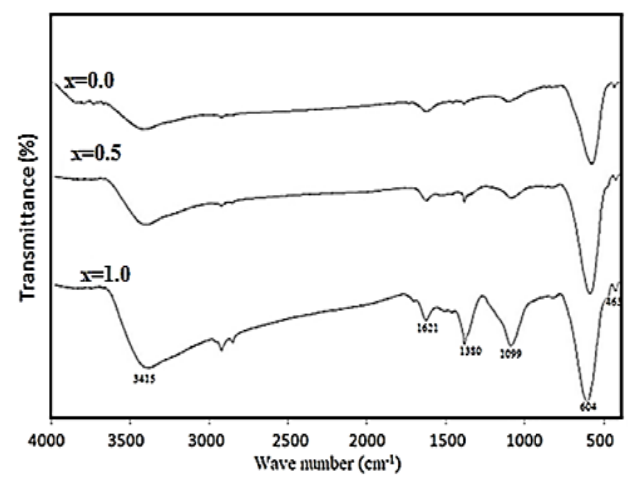

Figure 3. FTIR spectrums of $\mathrm{La}_{\mathrm{x}}, \mathrm{Co}_{0.2}, \mathrm{Sm}_{0.2}, \mathrm{Fe}_{2-\mathrm{x}} \mathrm{O}_{4}$, (where $\mathrm{x}=0.0,0.5,1.0$ ) nanoferrites

\subsection{Microstructure and elemental composition (SEM-EDX analysis)}

Surface morphology and micro structure of LCSF samples were studied using scanning electron microscope (SEM) and the corresponding SEM images of LCSF spinel nanoferrites at different concentrations (La_x,Co_0.2,Sm_0.2,Fe_(2-x) O_4, (where $\mathrm{x}=0.0,0.5,1.0$ ), (where $\mathrm{x}=0.0,0.5,1.0$ ) were shown in the Figure 4 (a-c). LCSF synthesized by Sol-Gel method the surface has compact structure and some nanoferrite particles were agglomerated, formed large clusters with various particle sizes less than $100 \mathrm{~nm}$. The Chemical composition of LCSF samples were determined by EDX technique and pattern obtain is shown in Figure 4. Figures 4 (a-c) right side shows the EDX patterns LCSF spinel nanoferrites at different concentrations including zero concentration of doping element La3+in Sm-Co nanoferrites, respectively [37]. Three figures reveal the presence of lanthanum (La) (except $4 \mathrm{a}$ where $\mathrm{x}=0.0$ ), Cobalt $(\mathrm{Co})$, Samarium (Sm), 
Oxygen $(\mathrm{O})$ and Iron $(\mathrm{Fe})$ peaks and final results tabulated in Table 2. From the table, it was identified that LCSF samples at different concentrations didn't contain any other elements as impurities. This indicate the $100 \%$ purity ofthe prepared LCSF sample.

Table 2. EDX analysis of [ La \_0.5,Co_0.2,Sm_0.2,Fe_1.5 O_4, (LCSF) nanoferrites

\begin{tabular}{cccc}
\hline Spinel nanoferrites & Element & $\mathrm{Wt}(\%)$ & Atomic Wt (\%) \\
\hline $\mathrm{La}_{0} \mathrm{Co}_{0.2}, \mathrm{Sm}_{0.2}, \mathrm{Fe}_{2} \mathrm{O}_{4}$ & $\mathrm{La}(\mathrm{K} \square)$ & 0.00 & 0.00 \\
& $\mathrm{Sm}(\mathrm{K} \square)$ & 19.27 & 19.99 \\
& $\mathrm{Co}(\mathrm{K} \square)$ & 20.67 & 22.67 \\
& $\mathrm{Fe}(\mathrm{K} \square)$ & 42.67 & 43.67 \\
& $\mathrm{O}(\mathrm{K} \square)$ & 17.39 & 13.67 \\
$\mathrm{La}_{0.5}, \mathrm{Co}_{0.2}, \mathrm{Sm}_{0.2}, \mathrm{Fe}_{1.5} \mathrm{O}_{4}$ & $\mathrm{La}(\mathrm{K} \square)$ & 2.37 & 2.69 \\
& $\mathrm{Sm}(\mathrm{K} \square)$ & 18.86 & 19.56 \\
& $\mathrm{Co}(\mathrm{K} \square)$ & 20.23 & 22.19 \\
& $\mathrm{Fe}(\mathrm{K} \square)$ & 41.76 & 42.74 \\
$\mathrm{La}_{1.0}, \mathrm{Co}_{0.2}, \mathrm{Sm}_{0.2}, \mathrm{Fe}_{1}, \mathrm{O}_{4}$ & $\mathrm{O}(\mathrm{K} \square)$ & 16.78 & 12.82 \\
& $\mathrm{Sm}(\mathrm{K} \square)$ & 2.49 & 2.82 \\
& $\mathrm{Co}(\mathrm{K} \square)$ & 17.92 & 18.59 \\
& $\mathrm{Fe}(\mathrm{K} \square)$ & 39.67 & 21.08 \\
& $\mathrm{O}(\mathrm{K} \square)$ & 20.70 & 40.60 \\
& & & 16.91 \\
\hline
\end{tabular}

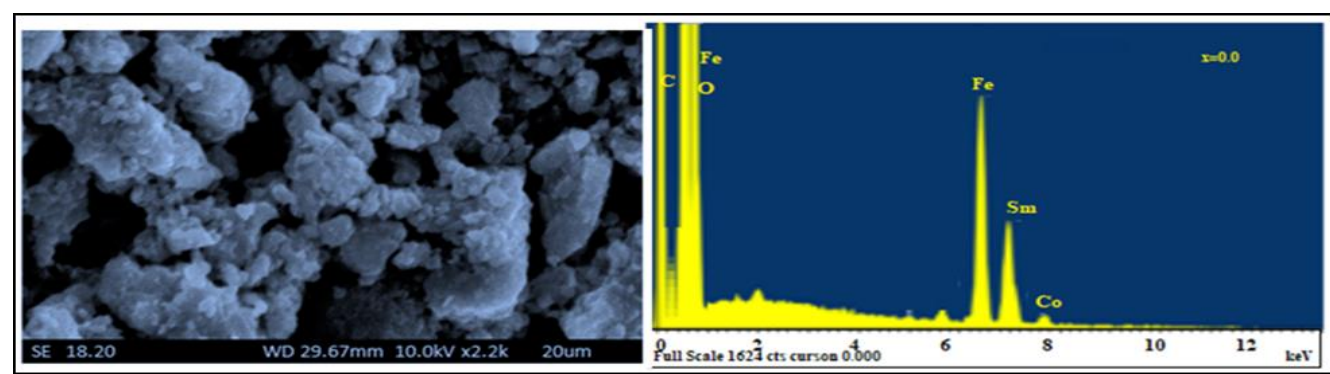

(a)

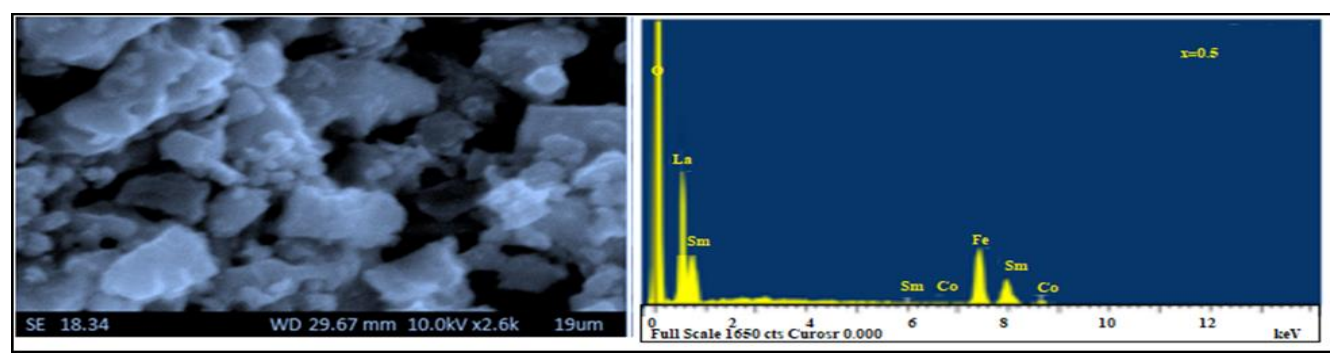

(b)
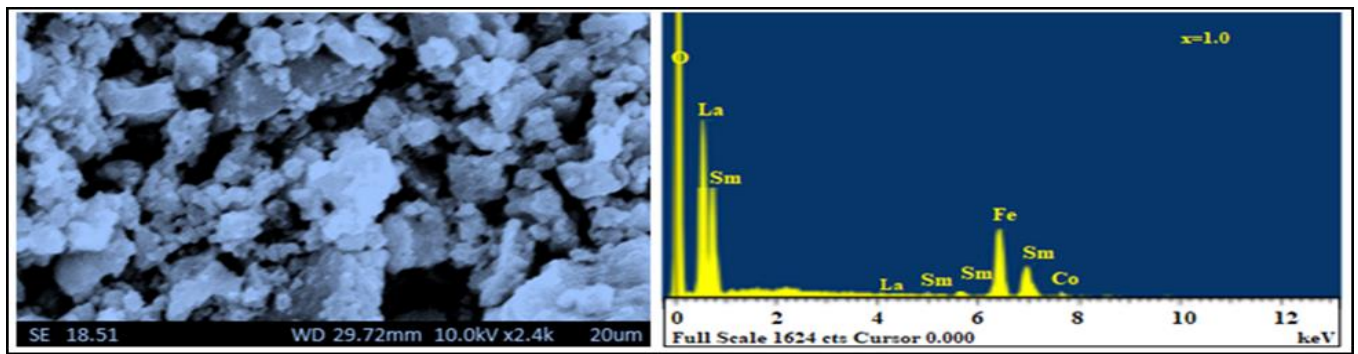

(c)

Figure 4. (a) SEM (left) and EDX (right) images of $\mathrm{La}_{0}, \mathrm{Co}_{0.2}, \mathrm{Sm}_{0.2}, \mathrm{Fe}_{2} \mathrm{O}_{4}$, (LCSF) nanoferrites, (b) SEM (left) and EDX (right) images of $\mathrm{La}_{0.5}, \mathrm{Co}_{0.2}, \mathrm{Sm}_{0.2}, \mathrm{Fe}_{1.5} \mathrm{O}_{4}$, (LCSF) nanoferrites, (c) SEM (left) and $\mathrm{EDX}$ (right) images of $\mathrm{La}_{1}, \mathrm{Co}_{0.2}, \mathrm{Sm}_{0.2}, \mathrm{Fe}_{1.0} \mathrm{O}_{4}$, (LCSF) nanoferrites 


\subsection{TEM-SAED analysis}

Transmission Electron Microscopy (TEM) analysis was carried to record the size of the ferrite particles in order to study surface properties and grain sizes. Figure 5, which confirm their nanocrystalline nature. TEM images La3+ substituted $\mathrm{Co}-\mathrm{Sm}$ nanoferrite, [La_x, Co_0.2, Sm_0.2, Fe_(2-x) O_4, (where $\mathrm{x}=0.0,0.5,1.0)]$ which seems the particles appear spherical in shape, agglomerated particles and some elongated particles are also present. The particle size was found to be, $22.1 \mathrm{~nm}(x=0) ; 23.4 \mathrm{~nm}(\mathrm{x}=0.5)$ $\mathrm{nm}$ and $26.4 \mathrm{~nm}(\mathrm{x}=1.0)$ for lanthanum substituted Co-Sm nanoferrites and which concurs well with the crystallite estimate estimated with XRD and guarantees the nano size nature of particles. SAED patterns for samples were also obtained and given in Figure 4, which one can clearly see the diffraction rings and affirms the consistency of particles in both morphology and size dissemination. Thus, microstructure studies are very important in order to explain the relationship between the processing parameter and the behavior of the materials used in practical applications. TEM-SAED analysis confirms the polycrystalline nature of the prepared nanoferrite as well as the uniformity of LCSF nanoparticles morphology and size distribution.
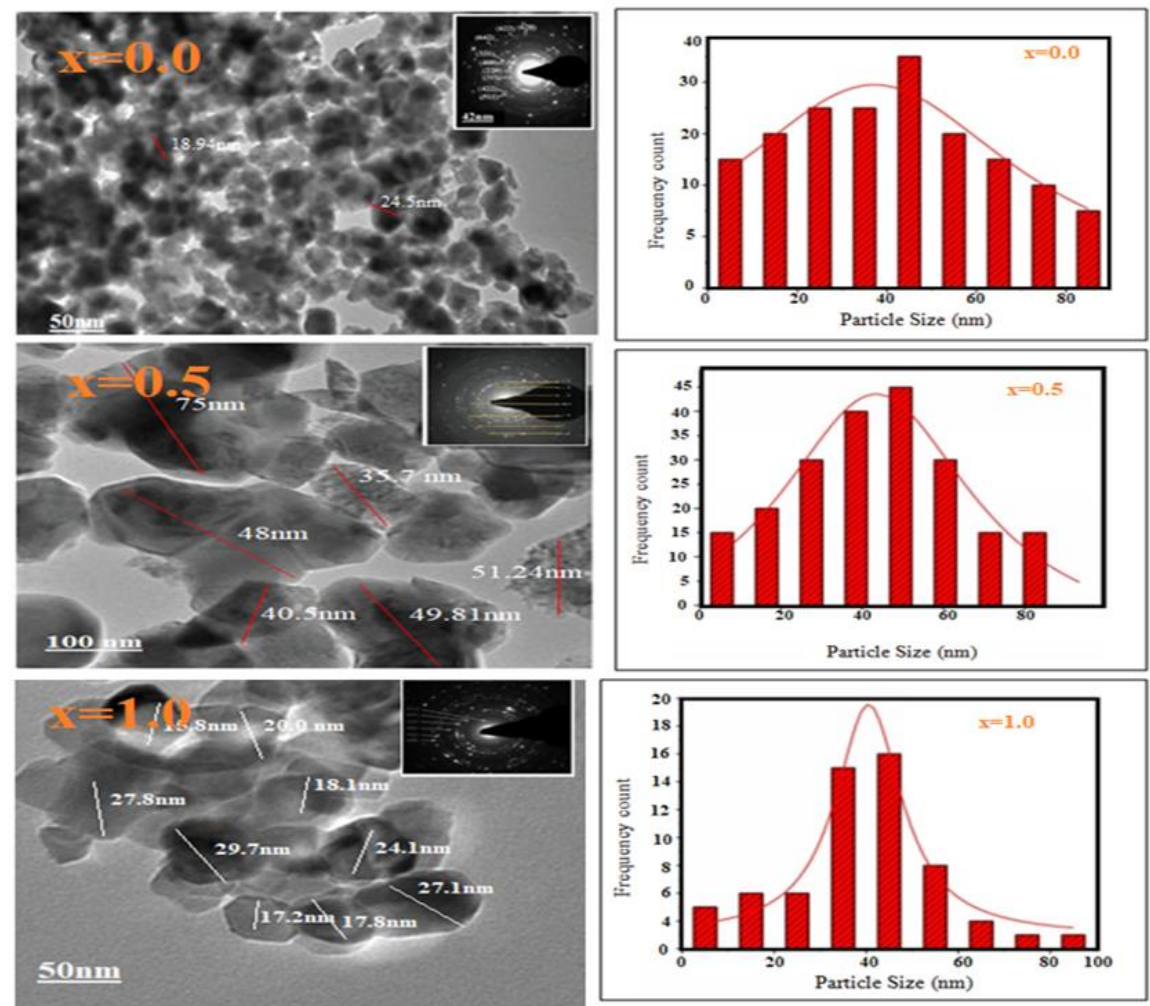

Figure 5. TEM-SAED images of Lanthanum substituted Co-Sm nanoferrites

$\left[\mathrm{La}_{\mathrm{x}}, \mathrm{Co}_{0.2}, \mathrm{Sm}_{0.2}, \mathrm{Fe}_{2-\mathrm{x}} \mathrm{O}_{4}\right.$, (where $\left.\left.\mathrm{x}=0.0,0.5,1.0\right)\right]$ along with particle size distribution graphs (right side)

\subsection{Magnetic properties}

The magnetic parameters of prepared LCSF nanoferrite samples were calculated using a vibrating sample magnetometer at vide range of Oe, where the samples exhibited the magnetic behavior. Figure 6 shows the typical magnetic hysteresis loops of LCSF (La_x,Co_0.2,Sm_0.2,Fe_(2-x) O_4) nano ferrite samples at different concentrations $\left(x=0.0,0.5\right.$ and 1.0) of $\mathrm{La}^{3+}$ as doping element on Sm-Co ferrite. The characteristic magnetic parameters are listed in Table 1. LCSF nanoferrite samples are ferromagnetic in nature manifests by the higher values $62.54 \mathrm{emu} / \mathrm{g}$ for $\mathrm{Sm}$-Co nanoferrite, which diminishes with expanding concentration of lanthanum particle $\left(\mathrm{La}^{3+}\right)$ as dopant in the ferrite samples. It is notable that magnetic minute in Lanthanum doped ferrites is because of associations between $4 \mathrm{fe} \square 3 \mathrm{~d}$ e- of unfilled $\mathrm{La}^{3+}$ shells. The substitution of substantial magnetic moment $\mathrm{La}^{3+}$ ions for $\mathrm{Fe}^{3+}$ ions should build the resultant magnetic moment hypothetically at ordinary temperatures. Be that as it may, in the present case, the decline in immersion polarization because of substantial substitution of $\mathrm{La}^{3+}$ ions at room temperature which create strain and debilitates $\mathrm{La}^{3+} \square \mathrm{Fe}^{3+}$ associations, thus lanthanum ferrites are considered as a few times nonmagnetic materials. 
- The coercivity H_(c)is the proportion of the magnetic field quality which is required to beating anisotropy to flip the magnetic minutes and it is plainly influenced by the La3+ doping in Sm-Co ferrites. The coercivity values of rare earth element La3+- doped samarium-cobalt nanoferrite samples vary from 1057.57, 1302.61 and1522.02 Oe. Obtained values in the current study are very much greater than the results obtained by the S. Chakravarty et al (2007) and M. M. Rashad et al (2008).

- The remnant ratio $R=M \_r / M \_s$ is an indication of the straightforwardness with which the direction of magnetization reorients to the closest axis magnetization heading after the magnetic field is evacuated. The calculated values of remnant ratio of LCSF samples are in the range from $0.308,0.345,0.498$ for $\mathrm{La}=0.0,0.5$ and 1.0 concentration respectively in LCSF nanoferrites suggesting the indication of decrease in anisotropy of crystal lattice.

- Presently the variety of penetrability with concentration can be comprehended, in qualitatively, utilizing the variety of magnetic saturation Figure 7 with concentration.

- The magnetic property examination results showed at $\mathrm{x}=0.5$, the rate with $\mathrm{La} 0.5, \mathrm{Co} 0.2, \mathrm{Sm0.2}, \mathrm{Fe} 1.5 \mathrm{O} 4$ claim an attractive highlights in contrasting with other LCSF samples due with its best hysteresis circuit all together, that it can understand the states of using it as a cores in transducers and electrical motors.

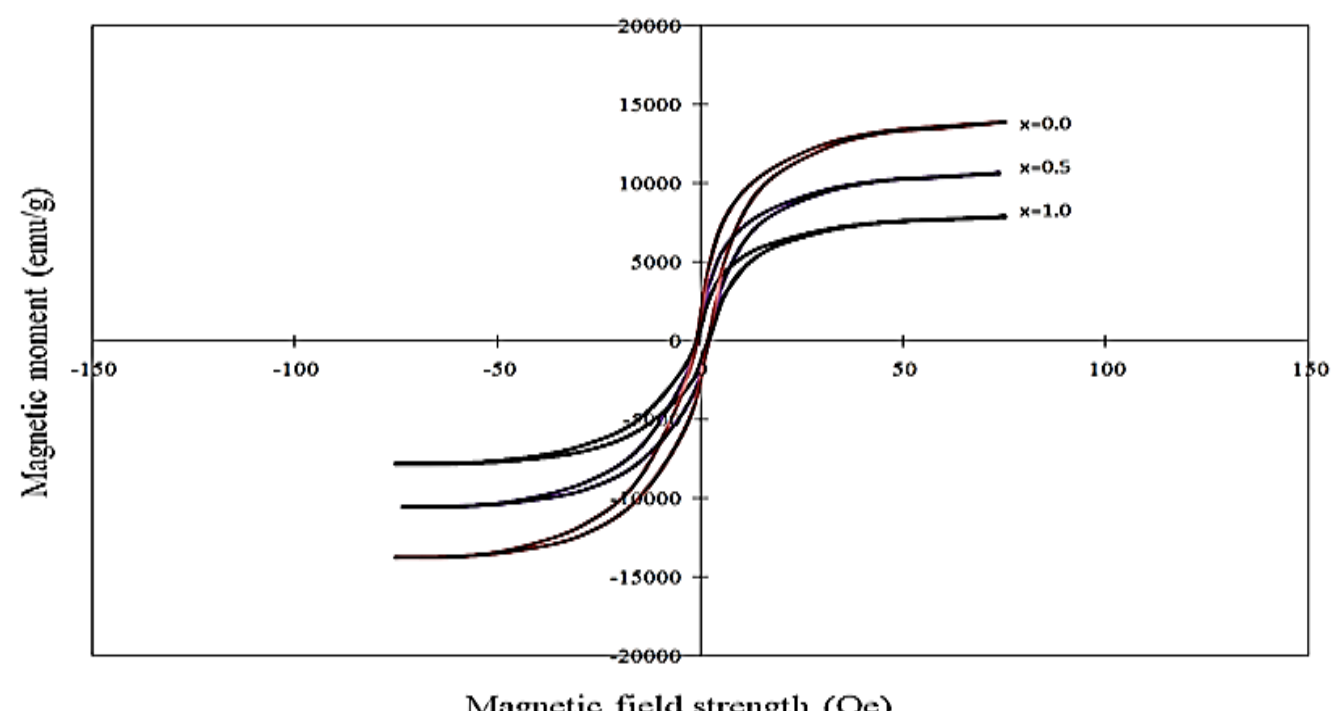

Figure 6. The hysteresis loops of Lanthanum substituted Co-Sm nanoferrites

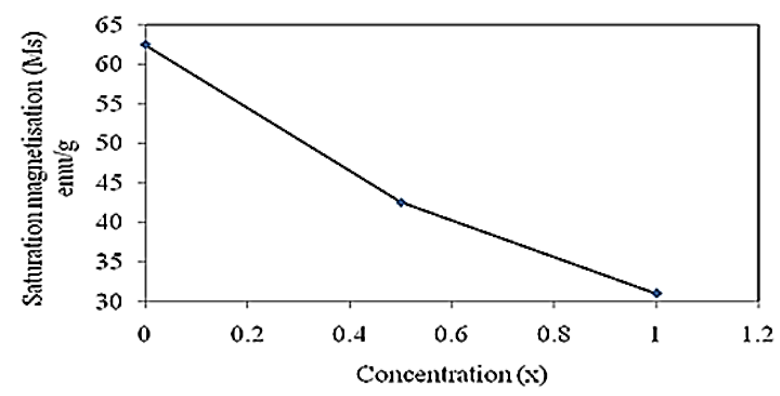

Figure 7. Variation of saturation magnetization $\left(\mathrm{M}_{\mathrm{S}}\right) \mathrm{Vs} \mathrm{La}^{3+}$ ions concentration

\subsection{Dielectric properties}

In the current study dielectric loss and dielectric frequency of three LCSF spinal ferrites calculated according to the method proposed by Smit and Wijn as function of frequency on HIOKI model No 3532-50 LCR HITESTER and the results were graphically represented in Figure 8 and Figure 9.

- The dielectric loss tangent $(\tan \delta$ ) decrease with an increase in frequency of LCSF nanoparticles as shown in Figure 8. This trend is generally explained based on jumping frequency of charge carriers can't follow the frequency of applied filed after specific frequency. 
- As indicated by Hudson (1978), $\tan \delta$ values in spinel ferrites are reflected in the conductivity estimations when the ferromagnetic materials with high conductivity demonstrate higher misfortunes and vice versa.

- Based on the results Figure 9, the dielectric constant decreases with increasing frequency. It was observed that the dielectric constant is high at lower frequency and then decreases rapidly finally stagnates at higher frequencies. This is the common behaviour of ferromagnetic elements with the evidence of Maxwell-Wagner model.

- According to Maxwell-Wagner model nanoferrites composed with two layers, in which upper layer (Fe2+ ions) is well conducting grains and the lower layer is made with poorly conducting ( $\mathrm{Fe}^{3+}$ ions) grain boundaries. Identified dielectric constant scenario is explained due to the space charge polarization generated inside the spinal particle by the availability of heterogeneous dielectric structure. Electron transport happened (electron hopping) between $\mathrm{Fe}^{2+}$ and $\mathrm{Fe}^{3+}$ located at crystallite sites i.e., Octahedral sites leads dielectric dispersion finally it leads to AC electrical field at higher frequencies. This is called hopping mechanism of the e- transfer.

- The low estimation of dielectric consistent and $\tan \delta$ is because of the substitution of lanthanum particle in Samarium-Cobalt nanoferrite might be disclosed due to bouncing (hopping) conduction process between $\mathrm{Fe}^{2+} \rightarrow \mathrm{La}^{3+}+\mathrm{e}^{-}$. The doping of lanthanum particles instead of iron/cobalt/samarium particles confines the level of conduction and polarization by blocking jumping process, coming about diminishing in conductivity, dielectric consistent and $\tan \delta$.

- Prepared materials characterized based on the dielectric loss and dielectric constant is suitable to prepare high frequency applications.

From the figures, it was identified that, three Samarium-Cobalt nanoferrites exhibiting the normal ferromagnetic behavior even at zero concentration of Lanthanum ion as doping agent.

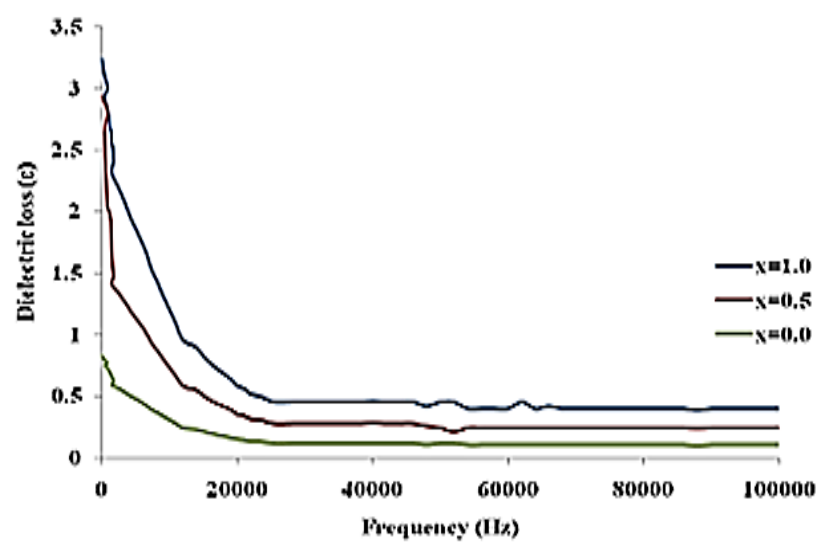

Figure 8. Variation of dielectric loss of LCSF spinel ferrites with frequency

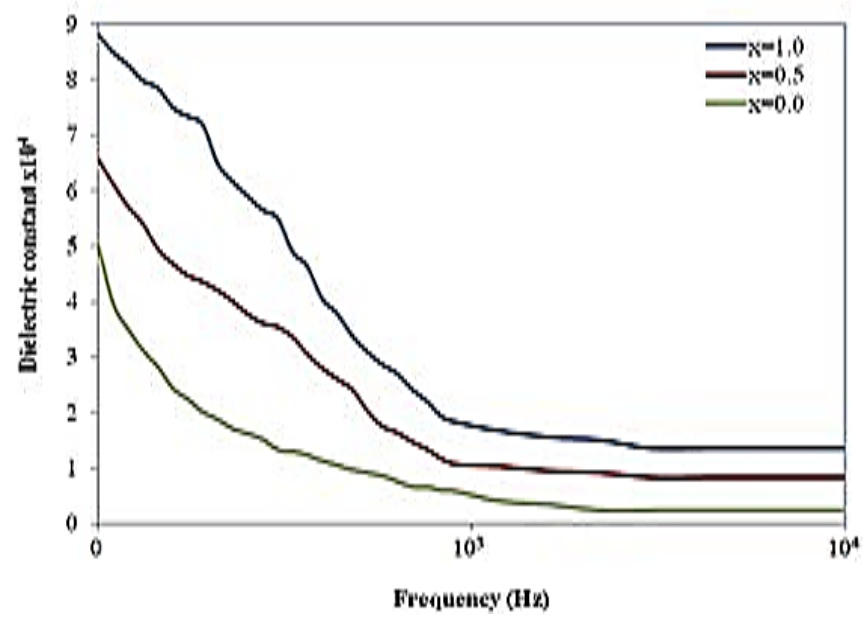

Figure 9. Variation of dielectric constant of LCSF spinel ferrites with frequency 


\section{CONCLUSION}

Finally, it was concluded that, LCSF nanoferrite samples with concentration of La=0.0, 0.5 and 1.0 in sol-gel method successfully synthesized at room temperature. The values of magnetization for the various concentrations of lanthanum are evident that the saturation magnetization decreases with the substitution of lanthanum. At the same time, it is worthy to recall that the XRD study too, indicated a considerable change in the crystallite size with increasing $\mathrm{La}^{3+}$ content.XRD examination confirms the existence of single-phase spinel nanoferrites structure without any secondary in all compositions. As $x$ values increases unit cell volume decreases leading to increase in X-ray density values. FTIR analysis confirms the chemical composition and bonding nature of LCSF samples SEM analysis predicts the inhomogeneous nature of particles and EDX study reveals the stoichiometry of LCSF nanoferrite samples prepared. Magnetization decreases due to surface effect and increasing rare earth ion concentration. LCSF nanoferrite samples exhibited a frequency independent behavior. Based on the studies properties and results make the prepared LCSF nanoferrites samples useful for the making of opto-magnetic devices, microwave devices, perpendicular recording media etc.

\section{REFERENCES}

[1] Ponce A.S. et al., "High coercivity induced by mechanical milling in cobalt ferrite powders", Journal of Magnetism and Magnetic Materials, Volume 344, Pages 182-187, October 2013.

[2] Yarilyn Cedeño-Mattei et al., "Effect of high-energy ball milling time on structural and magnetic properties of nanocrystalline cobalt ferrite powders", Journal of Magnetism and Magnetic Materials, Vol 341, pp 17-24, Sept 2013.

[3] M.Sajjia, M. Oubaha, M. Hasanuzzaman, A.G.Olabi, "Developments of cobalt ferrite nanoparticles prepared by the sol-gel process", Ceramics International, Volume 40, Issue 1, Part A, Pages 1147-1154, January 2014.

[4] T. Saragi et al., "Synthesis of Cobalt Ferrite Particles by Utilized Sol-Gel Method", Materials Science Forum, Vol. 827, pp. 219-222, 2015.

[5] Hayder A. Abbas, Adnan H. Ali, Ban M. Hasan, "Morphology and magnetic properties of lanthanum (La3+) substituted manganese, chromium nano ferrites", International Journal of Power Electronics and Drive System (IJPEDS), Vol. 10, No. 2, pp. 1102 1109, June 2019.

[6] M. Bradiceanu et al., "Cobalt Ferrite Nanostructures Obtained by Chemical Coprecipitation and Hydrothermal Method. Chem. Bull", "POLITEHNICA" Univ. (Timişoara), Volume 52(66), 1-2, 2007.

[7] P Annie Vinosha, L Ansel Mely, G Immaculate Nancy Mary, K Mahalakshmi, S Jerome Das, "Study on Cobalt Ferrite Nanoparticles Synthesized by Co-Precipitation Technique for Photo-Fenton Application", Mechanics, Materials Science, Engineering Journal, Magnolithe, 9(1), 2017.

[8] Ali, A.H., Abdul-Wahid, S.N., "Analysis of self-homodyne and delayed self-heterodyne detections for tunable laser source linewidth measurements", IOSR J. Eng. 2(10), 1-6, 2012.

[9] R.S.Melo et al., "Magnetic ferrites synthesised using the microwave-hydrothermal method", Journal of Magnetism and Magnetic Materials, Volume 381, Pages 109-115, 1 May 2015.

[10] Kanagesan, Samikannu \& Hashim, Mansor \& Subramani, Tamilselvan \& Alitheen, Noorjahan \& Ismail, Ismayadi \& Mustaffa, Syazwan \& Zuikimi, M.M.M.. (2013), "Sol-gel auto-combustion synthesis of cobalt ferrite and it's cytotoxicity properties", Digest Journal of Nanomaterials and Biostructures. Vol. 8, No. 4, pp. 1601-1610, 2013.

[11] BifaJI et al., "Magnetic properties of samarium and gadolinium co-doping $\mathrm{Mn}-\mathrm{Zn}$ ferrites obtained by sol-gel autocombustion method", Journal of Rare Earths, Vol. 34, Issue 10, pp 1017-1023, October 2016.

[12] Said M. Z, Hemeda D. M, Abdel kader S and Farag G. Z, "Structural, Electrical and Infrared Studies of Ni $0.7 \mathrm{Cd}$ 0.3 Sm Fe2O4 Ferrite", Turk J Phys, Volume 37, pp. 41-50, 2007.

[13] Jagdish Chand, Singh M., "Electric and dielectric properties of Mg Gd 0.1 Fe $1.9 \mathrm{O} 4$ ferrite", Journal of Alloys and Compounds, Volume 486, pp. 376-379, 2009.

[14] Samy A.M, Gomaa E. and Mostafa N, "Study the Properties of Cu-Zn Ferrite Substituted with Rare Earth Ions by Using Positron Annihilation Analysis", The Open Ceramic Science Journal, Vol. 1, pp. 1-4, 2010.

[15] Adnan H. Ali, Ali N. Abbas, M. H. Hassan, "Performance Evaluation of IEEE 802.11g WLANs Using OPNET Modeler", (AJER) Volume 02, Issue 12, pp. 09-15, 2013.

[16] M.Sivabharathy et al, "Synthesis Of Double Lanthanide Doped Nano Ferrite Meta Material For Microstrip Patch Antenna ApplicationInt”, J. Chem Tech Res. 6(11),pp 4615-4624, 2014.

[17] Rezlescu N, Rezlescu E, Pasnicu C, and Craus M.L, "Effect of the rare-earth ions on some properties of nickel-zinc ferrite', J. Phys. Condens. Matter, Volume 6, pp. 5707, 1994.

[18] Sattar A.A. and. El-Shokrofy K.M, "Rare Earth Doping Effect on the Electrical Properties of Cu-Zn Ferrites", Phys. IV France, Volume 07, pp. C1-245-C1-246, 1997.

[19] Adnan. H. Ali, "Simultaneous measurements for tunable laser source linewidth with homodyne detection", Comput. Inf. Sci., vol. 4, no. 4, pp. 138-144, Jul. 2011.

[20] Sichu Li and Vijay T. John, "Cobalt-ferrite nanoparticles: Structure, cation distributions, and magnetic properties", Journal of Applied Physics 87, 6223 (2000), 28 April 2000, https://doi.org/10.1063/1.372661.

[21] B P. Scherrer, "Bestimmung der Grösse und der inneren Struktur von Kolloidteilchen mittels Röntgenstrahlen," Nachr. Ges. Wiss. Göttingen 26, Volume: 1918, page 98-100, 1918. 
[22] Sheena Xavier, Smitha Thankachan, Binu P. Jacob, and E.M.Mohammed, "Effect of Samarium Substitution on the Structural and Magnetic Properties of Nanocrystalline Cobalt Ferrite", Journal of Nanoscience, Volume 2013, Page No 1-7, 2013, http://dx.doi.org/10.1155/2013/524380.

[23] B. G. Toksha, S. E. Shirsath, S. M. Patange, and K. M. Jadhav, "Structural investigations and magnetic properties of cobalt ferrite nanoparticles prepared by sol-gel auto combustion method," Solid State Communications, vol. 147, no. $11-12$, pp.479-483, 2008.

[24] Ali A. Abdulrazzaq, Adnan H. Ali, "Efficiency Performances of Two MPPT Algorithms for PV System with Different Solar Panels Irradiances", International Journal of Power Electronics and Drive System (IJPEDS) Vol. 9 , No. 4, pp. 1755 1764, December 2018.

[25] L. Zhao, H. Yang, L. Yu, Yuming, X. Zhao, S. Feng, "Magnetic properties of Re-substituted Ni-Mn ferrite nanocrystallites," J. Mater. Sci. Volume 42, Issue 2, pp 686-691, January 2007.

[26] L. Ben Tahar, M. Artus, S. Ammar, L.S. Smiri, F. Herbst, M.J. Vaulay, V. Richard, M. Greneche, F. Villain, F. Fievet, J. Magn. Magn. Mater. 320, 3242, 2008.

[27] J. Smit and H. P. J. Wijn, Ferrites, "Philips Technical Library Eindhoven," The Netherlands, 1959.

[28] Ahmed MA, Mansour SF, El-Dek SI., "Investigation of the physico-chemical properties of nanometric NiLa ferrite/PST matrix”, Solid State Ionics. Vol. 181, Issue 25-26, pp:1149-1555, 2010.

[29] Sivakumar P, Ramesh R, Ramanand A, Ponnusamy S, Muthamizhchelvan C., "Preparation of sheet like polycrystalline $\mathrm{NiFe} 2 \mathrm{O} 4$ nanostructure with PVA matrices and properties". Materials Letters. 65(9):1438-1440, 2011.

[30] A. Gadkari, T. Shinde, P. Vasambekar,'Influence of rare-earth ions on structural and magnetic properties of CdFe2O4 Ferrites", Rare Metals 29 pp.168-173, 2010.

[31] M. Raghasudha, D. Ravinder, P. V., "FTIR Studies and Dielectric Properties of Cr Substituted Cobalt Nano Ferrites Synthesized by Citrate-Gel Method", Nano science and Nanotechnology, 3(5): 105-114, 2013.

[32] X. Zhao, Wei Wang, Y. Zhang, Sizhu Wu, Feng Li, J. Ping Liu, "Synthesis and characterization of gadolinium doped cobalt ferrite nanoparticles with enhanced adsorption capability for Congo Red", Chem. Eng. J. 250, 164e174, 2014.

[33] M. M. Rashad, R. M. Mohamed, and H. El-Shall, "Magnetic properties of nanocrystalline Sm-substituted CoFe2O4 synthesized by citrate precursor method," J. of Materials P. Technology, vol. 198, no. 1-3, pp. 139-146, 2008.

[34] S. E. Shirsath, B. G. Toksha, and K. M. Jadhav, "Structural andmagnetic properties of In3+ substitutedNiFe2O4," Materials Chemistry and Physics, vol. 117, no. 1, pp. 163-168, 2009.

[35] Smit J., Wijn H. P. J., "Electrical properties, in: Ferrites. Physical properties of ferromagnetic oxides in relation to their technical applications", Philips technical Library Eindhoven, The Netherlands, p. 239, 1959.

[36] Adnan H. Ali, Farhood, A.D., "Design and Performance Analysis of the WDM Schemes for Radio over Fiber System with Different Fiber Propagation Losses", Fibers, 7, 19, 2019.

[37] M. Bhuvaneswari et al., "Synthesis, investigation on structural and electrical properties of cobalt doped Mn- $\mathrm{Zn}$ ferrite nanocrystalline powders", Materials Science-Poland, 34(2), pp. 344-353, 2016. 